\title{
Analysis of Corporate Competition Strategies and Marketing Strategies in English Training Market in China
}

\author{
Taking New Oriental Education and Wall Street English as \\ Examples
}

\author{
Peng $\mathrm{Wei}^{1, *}$
}

${ }^{1}$ The University of Sheffield, S3 7SS, Sheffield, the UK

*Corresponding author. Email: wpeng10@sheffield.ac.uk

\begin{abstract}
Due to thirty years of reform and opening up, the market dividends have promoted the rapid rise of English education industry in China. Nowadays, with the global economic integration and the accelerated development of the knowledge economy, the industry will face new market challenges and opportunities. This article utilizes methods of existing theoretical review, literature analysis and actual case studies, by taking New Oriental Technology Education Group and Wall Street English (China) as examples to compare their development, competitive sand marketing strategies, analyzing the advantages and disadvantages of them, and finally giving suggestions for their market development. This study found that the formulation of scientific and reasonable corporate strategies and the implementation of effective market strategies are significant to enhance the competitiveness and profitability of enterprises and ultimately realize their sustainable development.
\end{abstract}

Keywords: English education industry, PEST, Corporate marketing strategy, Corporate development strategy, Corporate competitive strategy.

\section{INTRODUCTION}

Since China opened up in 1992, especially after China acceded to the WTO, the market's demand for English-speaking talents has been increasing. And it has created unprecedented prosperity and development of China's English education industry and has made several well-known Chinese and foreign English training institutions, such as New Oriental Education, Wall Street English, and so forth. According to China's National Bureau of Statistics, the overall number of students from preschool to postgraduate reached 6,487 million in 2019 [1]. It is estimated that by 2020, China's English training market will exceed 100 billion yuan [2], which will create huge market demand and business opportunities in the industry. However, fierce market competition and complex geographical differences have resulted in the life cycle of most educational institutions being only 2 to 3 years. Therefore, how to formulate a scientific corporate strategy and implement an efficient marketing strategy are exceptionally vital for promoting the sustainable development of the company and maintaining competitive advantages and producing profits.

Based on the existing theories and the current situation of the industry, this article will conduct an in-depth study through analyzing New Oriental Education and Wall Street English's development, competition and marketing strategies, exploring their strengths and weaknesses, and giving corresponding reasonable suggestions.

\section{OVERVIEW}

\subsection{Background Information of Enterprises}

Wall Street English was founded by Italian Luigi Tiziano in Maryland, the USA in 1972. It 
mainly provides high-end English training for professionals and companies. The market has covered 28 countries and regions around the world. Although it also involves examination training and children's primary education, the scale of them are quite limited; this article will not analyze this field. Wall Street English entered China in 2000. At present, it has built 75 English learning centers in 11 cities, including Beijing, Shanghai and Guangzhou, serving more than 100,000 students in this market. It is the first English training institution in the world that gets an international ISO9001:2000 quality management system certification. After several capital operations, in 2018, it was acquired by the investment company Baring Asia and CITIC Capital from Pearson [3]. This article mainly focuses on Wall Street English's market development in China, hereinafter referred to as Wall Street.

Yu Minhong founded a new Oriental Education Technology Group (hereinafter referred to as New Oriental) in Beijing in 1993. It has been recognized as the largest comprehensive education group across the world. Its specific business includes foreign language training, elementary and secondary education, preschool education, online education, overseas consulting, book publishing, etc. In addition, it has some sub-brands, such as Youneng Middle School Education, Bubble Children's Education, Future Overseas Consulting, Xuncheng Online Education, Dayu Culture Publishing, Starry Star Parent-child Education, and re-reading of the same text college entrance examination. It was listed on the New York Stock Exchange in the United States in 2006, becoming China's first education and training institution to be listed overseas. As of 2020, New Oriental has been set up 104 schools, 12 bookstores and 1465 learning centers with more than 41400 teachers in 91 cities in the country; students face to face over a total of 5540 million passengers [4].

\subsection{The Status of Market Industry and Its Misunderstandings}

The current consumer groups in this market consist of students and professionals. The products and services of this industry mainly include study abroad training (TOEFL, IELTS, GRE, etc.), basic English courses (mainly K12 education), college English exams (level four, six and professional level eight), oral communication training, and professional English training [5]. Nevertheless, most learners are too utilitarian and they do not care about the actual language proficiency [5]. This has also led to a large number of institutions often neglecting the scientificity and rationality of their strategies and long term and sustainable development.

\subsection{Review and Analysis of Related Theories}

PEST theory is mainly used to analyze a company's external macro-environment, including aspects of political, economic, social, technological [6]. Porter's five forces analysis model is often used by companies to analyze specific industry market environments: the bargaining power of suppliers and buyers, the threats of existing and potential entrants, the risks of substitutes [7]. This five forces jointly determine enterprises' competitiveness and profitability. In the existing corporate strategic theories, they can be mainly divided into corporate strategic management theory, corporate development strategy theory, and corporate competitive strategy theory. This article mainly analyzes the corporate strategies from the perspective of enterprise development and competition.

Enterprise development strategies are mainly categorized as integrated strategies (horizontal, forward and subsequent items), diversification strategies (related diversification and non-related diversification), intensive growth strategies (market penetration, market and product development), and stable strategies, Contraction strategy. The competitive theory consists of lower cost, differentiation, and focus strategies [8]. 4P marketing theory mainly refers to a product, price, place, promotion, which is a combination of market strategy [9].

\section{COMPARISON OF THE TWO COMPANIES}

\subsection{Macro Market Environment}

From the perspective of the political climate, the Chinese government vigorously advocates a learning society and has issued several laws and policies to promote education reform. According to the view of the economic environment, China's total economic output has ranked second in the world, and residents' disposable income and family education investment has been increasing year by year. At the same time, international capital investment is also rising in this industry. Analyzed from the perspective of social culture, China has 
increased its investment in education every year; Due to the academic pressure and intense competition in workplaces, the demand for English training has been gradually increasing. From the technical perspective, the development and application of information technology, digitally online or offline teaching models, especially the 2019 global COVID-19 crisis, will further promote the reform and development of the education industry.

\subsection{Corporate Development Strategy}

In terms of development strategy, Wall Street English (China) adopts a stable market development strategy by taking Beijing, Shanghai, Guangzhou, Shenzhen and other cities as its core markets, and gradually expands to its market around these cities. New Oriental Education mainly implements integrated and diversified development strategies. Through horizontal integration development strategy, it integrates high-quality resources in the same industry, applying a vertical integration strategy to build its own fully controlled upstream and downstream supply chain in this market.

\subsection{Corporate Competitive Strategy}

From the scope of competition strategy, Wall Street English (China) adopts a method of focusing

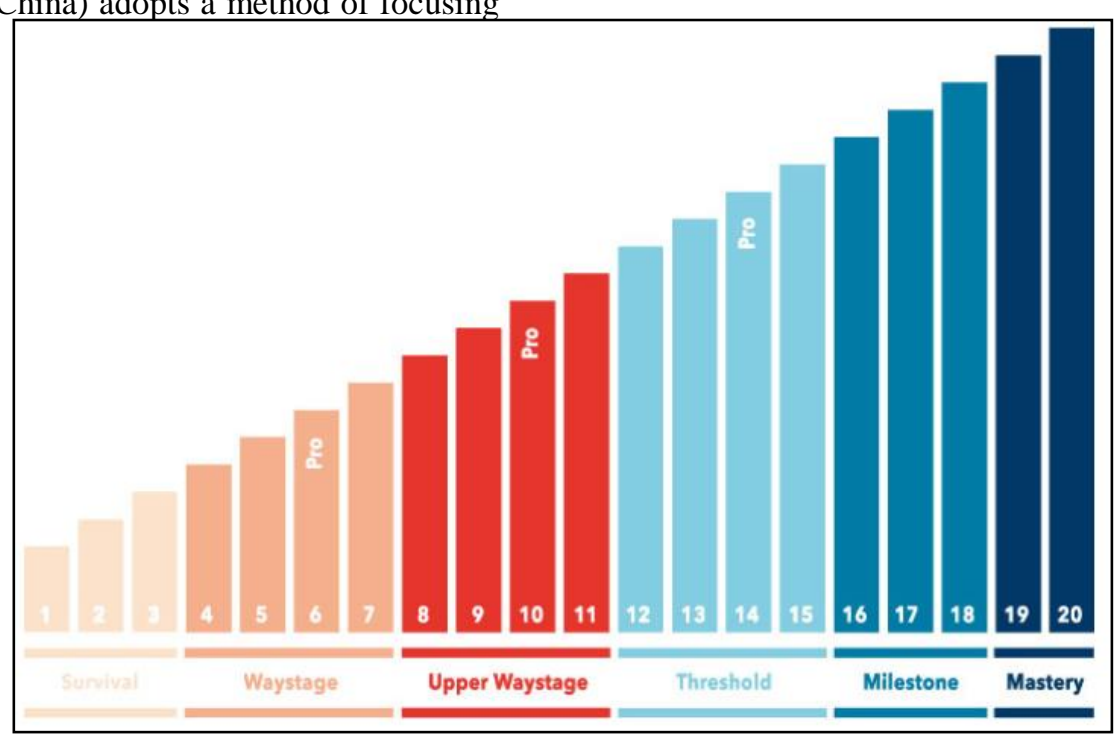

Figure 1 Wall Street English's course category.

In terms of product strategy, New Oriental first adopted an approach of course segmentation and hierarchical division for different target customer groups. As of 2020, its business types mainly include OMO education, online education, primary on competition, concentrating resources to mainly develop the coastal areas of China and other economically developed cities for market expansion and business development. New Oriental Education adopts the lower-cost strategy, taking the advantages of its current operation management system based on its headquarter in Beijing, rapidly constructing its wide-ranging market layout in China's provincial capitals and prefecture-level cities, thereby forming a relatively lower cost and price advantages.

\subsection{Corporate Marketing Strategy}

\subsubsection{Product Strategy}

Wall Street English adopts its unique multielement method teaching system, providing customers with exclusive custom, one-site service, classroom courses, online and offline teaching and other English training services in flexible and adjustable time to meet the individual needs of customers. This system is divided into six stages and 20 levels based on difficulty degree and level. (see "Figure 1") 
essential carrier for delivering the value of products and services. Finally, New Oriental values periodic compensation and complementarity of products and responds to market or policy changes in time through continuous research and development and updating its curriculum products.

\subsubsection{Pricing Strategy}

Wall Street English (China) mainly takes product market positioning, market status, and

Table 1. Overall prices competitive product prices as the reference basis for pricing, adopts high-price strategies (pricing at a single level), combined pricing strategies (two levels or more), Pricing strategy (offering regular discounts) based on consumer psychology. Its specific price ranges from 17,800 yuan to 36,800 yuan. (see "Table 1")

\begin{tabular}{|l|l|l|l|}
\hline \multicolumn{1}{|c|}{ Level } & \multicolumn{1}{|c|}{ Yuan/year } & \multicolumn{1}{c|}{ Level } & \multicolumn{1}{c|}{ Yuan/year } \\
\hline One level & 17,800 & Four levels & 28800 \\
\hline Two levels & 20800 & Five levels & 32800 \\
\hline Three levels & 24800 & Six levels & 36800 \\
\hline
\end{tabular}

New Oriental sets its course training prices based on the type of exam, class size, and duration, combined with the consumption power and actual needs of different students, and at the same time, concerning the market pricing of competitors. The following is a selection of the prices of some of its courses [9]. (see "Table 2")

Table 2. Course prices

\begin{tabular}{|l|l|l|}
\hline \multicolumn{1}{|c|}{ Category } & \multicolumn{1}{|c|}{ Yuan / Class } & \multicolumn{1}{c|}{ Person or hours } \\
\hline IELTS 6.5 & $¥ 5880$ & 25 person \\
\hline IELTS 6.5 & $¥ 18800$ & 6 person \\
\hline I heard that Crash Level 1 & $¥ 3750$ & 15 hours \\
\hline I heard that Crash Level 4 & $¥ 4750$ & 28 hours \\
\hline TOEFL Undergraduate Through Train Starting Class & $¥ 49800$ & 72 hours \\
\hline TOEFL Undergraduate Through Train Intermediate Class & $¥ 38800$ & 48 hours \\
\hline
\end{tabular}

\subsubsection{Channel Strategy}

In terms of channel marketing, Wall Street English (China) mainly utilizes its directly managed training centers as the primary channel to conduct various marketing activities to ensure its training quality and brand image. Additionally, it adopts the strategy combining point, line and surface to promote market expansion steadily. To be specific, it firstly selects areas to open training centers, which are within convenient transportation and prosperous business districts in different cities, which gives priorities to the development of first-tier developed cities such as Beijing, Shanghai, Guangzhou, Shenzhen, and Tianjin, to complete linear market coverage in the northern, southern, and eastern of cities in China, finally developing new markets around these developed cities to meet their whole market layout.

New Oriental's market layout is centred on Beijing, and then the market is rapidly expanded to various provincial capitals and other prefecture-level cities in China. Its specific business is also conducted in a direct sales model. New Oriental almost masters the entire industrial structure chain from product research and development, marketing, course training and after-sales service, and conducts channel marketing activities through New Oriental schools established in various cities.

\subsubsection{Promotion Strategy}

Regarding promotion strategies, Wall Street English (China) mainly adopts TV advertising, booth promotion, online and outdoor advertising promotion, unified corporate image and public relations maintenance.

New Oriental hardly involves TV advertising promotion, but it uses print media, online media and a large amount of outdoor advertising to conduct direct or indirect corporate promotions. Furthermore, it shows public relations marketing strategies to establishes a brand image and stimulates interest in learning. For instance, donating to Hope Primary School, setting up scholarships for needy students, and propagating inspirational stories from the founders. 


\section{DISCUSSION AND SUGGESTIONS}

The overall analysis demonstrates that the two institutions face the same external environment and favourable policies and situations in China. The only difference is that New Oriental is listed in the United States as a concept stock and faces the supervision of financial institutions in both China and the United States, and its business flexibility is relatively weak compared to Wall Street English. They all need to pay attention to how to adjust the company's strategies and market policies in time by changes in the external market environment.

\subsection{Market Development Strategy}

The stable market development strategy of Wall Street English is beneficial to reducing investment risks. However, the slow market layout will increase the cost and competitive pressure of its later market development. New Oriental's development strategy is conducive to rapid market deployment, improving market bargaining and the ability to cope with potential market competition and threats; however, the excessive market expansion will lead to increased enterprise costs, low profitability, untimely talent training, and lower training quality. Therefore, Wall Street should gradually develop new markets while stabilizing the existing markets. New Oriental needs to make a scientific and reasonable market layout based on its funds and personnel.

\subsection{Focus Strategy}

Focus strategy of Wall Street English (China) can concentrate on corporate resources to compete in the market. The management is relatively simple, and it is not easy to cause funding waste; nevertheless, the market coverage is lagging, which is not conducive to the development and layout of later market segments. In contrast, New Oriental's lower-cost strategy is beneficial to reducing corporate expenses and market prices, resisting price competition from competitors, increasing market share, and maximizing corporate profits through taking advantage of economies of scale. However, rapid expansion is not conducive to corporate management and leads to increased operating costs, even lead to a loss. Therefore, Wall Street needs to maintain its competitive advantages, and the New Oriental Group should focus on issues such as new market management, business development and market profitability.

\subsection{Product Strategy}

In terms of product strategy, Wall Street provides customized curriculum, class styles and flexible schedules, which can quickly meet different individual needs of customers in market segments; nonetheless, a single centred diversified teaching system is not easy to innovate its curriculum in the long run and update courses timely. New Oriental's product categories are comprehensive and diverse, which are updated in time. Thus, they are quite attractive to student groups, they aim to enter or study abroad, and have certain competitive advantages in the short term in workplaces. However, in the long run, it is easy to be copied and imitated by peers. Therefore, both Wall Street and New Oriental need to innovate their products, keep pace with the times, and improve product competitiveness in their respective market segments.

\subsection{High Pricing Strategy}

Wall Street's high pricing strategy is constructive to consolidating high-end brand image and is attractive to professionals and companies with higher spending power. Nonetheless, it may cause the loss of most potential customers, which is adverse to the later market layout and product adjustment. New Oriental's pricing is mainly in the low-end, which is in line with public consumption expectations and is conducive to market layout and customer acquisition; however, due to the fierce market competition, its profits would become lower, even forming a pattern of "small profits but quick turnover". Therefore, Wall Street should win customers through price promotions, and while enjoying price advantages, and New Oriental should provide high-quality services and diversified added value to resist market price competition.

\subsection{Channel Strategy}

In terms of channel strategy, Wall Street and New Oriental both adopt a direct sales model, directly under the headquarters, and use their respective training centers as their primary channels for sales. The main difference between them is that New Oriental emphasizes the control of the entire industry chain, which is useful to increasing market bargaining and the ability to meet challenges; nonetheless, it may lead to high costs, increased uncertainty in operation and management, and talent training that cannot keep up with development. Wall Street's control over the entire market industry chain is relatively single, even outsourcing its human 
resource management system, which can effectively reduce operating costs; nevertheless, it will affect its market bargaining power and increase market competition pressure. Therefore, both of them need to pay attention to the cost control in channel marketing and strengthen the training of management and teaching talents.

From the perspective of overall promotion methods and comparison of effects, Wall Street mainly adopts conventional promotion forms, which can lower cost but weak its market competitiveness, and it is difficult for some potential customers to distinguish and make final consumption choices. New Oriental Education focuses on the maintenance of public customer relations based on traditional promotional forms, and the forms are diverse. This is conducive to the formation of psychological interactions between customers and the resonance or recognition of values, thereby obtaining more potential customers in the market. In the long run, the two companies still need to pay attention to the innovation of promotion strategies and the diversification of their forms, mainly to keep pace with the times in the current information age, to win market customers and enhance their market competitiveness.

\section{CONCLUSION}

Development strategy is a long-term, overall, and basic design for enterprise development, which determines the medium and long-term development direction and market business category of the enterprise. The competitive strategy determines how an enterprise can compete with its peers in the market and obtain the most significant competitive advantage. Marketing strategy determines how the market uses products, pricing, channels, promotion and other methods to bring products or services to the market. In the complex, changeable and fast-growing Chinese English education and training industry, both Wall Street English (China) and New Oriental need to take their existing corporate advantages while formulating more scientific and reasonable development, competition, and marketing strategies based on its background, strengthens, weaknesses, opportunities and threats, thereby promoting sustainable development of marketers and ultimately creating corporate profits in the market.

\section{AUTHORS' CONTRIBUTIONS} Wei.

\section{ACKNOWLEDGMENTS}

In this thesis writing, from the topic selection, thesis structure, theoretical analysis, data and information investigation, etc., I received the patient guidance and great help from Teacher Zhang Jingjing, thus forming a complete structure and thesis writing ideas, and finally making this thesis successfully completed. In particular, she puts forward a lot of positive and useful opinions on how to connect the specific company strategies and marketing strategies of the two educational institutions. Here, special thanks to Miss Zhang.

\section{REFERENCES}

[1] Official statistics [Online] Available, retrieved from

https://data.stats.gov.cn/easyquery.htm?cn=C01 $\& z b=A 010303 \& s j=2019$, accessed on October 28,2020 .

[2] Research Report on the Strategy of Training Industry from Export to Domestic Market, p.30, 2020.

[3] Statistics [Online] Available, retrieved from http://www.wselearning.com, accessed on October 28, 2020.

[4] Statistics [Online] Available, retrieved from http://www.xdf.cn/ Accessed on October 28, 2020.

[5] J. M. Liang, Y. Y. Zhang, Y. Tian (2012). Misunderstanding of Domestic English Training Industry and Its Coping Strategies, China Academic Journal Electronic Publishing House. DOI:10.14018/j.cnki.cn13-1085/n.2012.23.076

[6] Ho, J. K. K. (2014). Formulation of a systemic PEST analysis for strategic analysis. European academic research, 2(5), pp.6478-6492.

[7] Porter, M. E. (2008). The five competitive forces that shape strategy. Harvard business review, 86(1), pp.25-40.

[8] Segev, E. (1989). A systematic comparative analysis and synthesis of two business - level strategic typologies. Strategic Management Journal, 10(5), pp.487-505.

[9] Prices of New Oriental's Courses [Online] Available, retrieved from http://www.sxcfwy.com/2222.html, accessed on October 28, 2020. 